\title{
One Step Electrodeposition of Graphene-Au Nanocomposites for Highly Sensitive Electrochemical Detection of Salbutamol
}

\author{
Xiu-Chun Guo ${ }^{1, \dagger}$, Hai-Hui Wang ${ }^{2, \dagger}$, Xuan-Jie Chen ${ }^{1}$, Zhao-Yang Xia ${ }^{1}$, Wen-Yi Kang ${ }^{1}$, Wen-Hui Zhou ${ }^{2, *}$ \\ ${ }^{1}$ Institute of Chinese Materia Medica, Henan University, Kaifeng 475004, China. \\ ${ }^{2}$ The Key Laboratory for Special Functional Materials of MOE, Henan University, Kaifeng 475004, \\ China. \\ *E-mail: zhouwh@henu.edu.cn, zhouwh@foxmail.com \\ $\dagger$ These two authors contributed equally to this work.
}

doi: $10.20964 / 2017.02 .29$

Received: 29 October 2016 / Accepted: 8 December 2016 / Published: 30 December 2016

\begin{abstract}
A simple and available strategy was developed for one step electrodeposition of graphene-Au (G-Au) nanocomposites which could be used for highly sensitive electrochemical detection of salbutamol. G$\mathrm{Au}$ nanocomposites were simultaneously deposited on glassy carbon electrode by one step electrodeposition method. This resulting G-Au nanocomposites modified electrode was characterized by different methods. Compared to graphene or Au nanoparticles (AuNPs) modified electrodes, this G$\mathrm{Au}$ nanocomposites modified electrode dramatically promote the electrooxidation of salbutamol on electrode surface and significantly enhance the differential pulse voltammetry (DPV) current response towards salbutamol. In addition, this one step electrodeposition method improved the stability of the modified G-Au nanocomposites layer. This constructed G-Au nanocomposites based electrochemical sensor exhibits high sensitivity and good selectivity for salbutamol, which may introduce by the synergistic effect of G-Au nanocomposites. Under optimized conditions, the constructed salbutamol sensor showed two linear dynamic ranges $(0.05-10 \mu \mathrm{M}$ and $20-200 \mu \mathrm{M})$. The linear range and sensitivity of the proposed salbutamol electrochemical sensors are better than other reported values. Moreover, this electrochemical sensor has been successfully applied to the determination of salbutamol in salbutamol sulfate injections with satisfied recoveries $(95.4 \%$ to $103.1 \%)$ and precision $(1.5 \%$ to $4.6 \%$ of RSD).
\end{abstract}

Keywords: Salbutamol; Graphene-Au nanocomposites; One step electrodeposition; Electrochemical sensor. 
(C) 2017 The Authors. Published by ESG (www.electrochemsci.org). This article is an open access article distributed under the terms and conditions of the Creative Commons Attribution license (http://creativecommons.org/licenses/by/4.0/). 